\title{
A THERAPEUTIC MANEUVER FOR OROPHARYNGEAL DYSPHAGIA IN PATIENTS WITH PARKINSON'S DISEASE
}

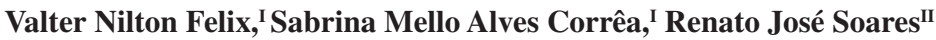

doi: 10.1590/S1807-59322008000500015

Felix VN, Corrêa SMA, Soares RJ. A therapeutic maneuver for oropharyngeal dysphagia in patients with Parkinson's disease. Clinics. 2008;63(5):661-6.

OBJECTIVE: This study investigates resources to provide better conditions for oropharyngeal swallowing for improvement in the quality of life of Parkinson's disease patients.

METHOD: Three men and one woman with an average age of 70.25 years had been afflicted with Parkinson's disease for an average of 9.25 years. The patients were submitted to a rehabilitation program for oropharyngeal dysphagia after a clinical evaluation of swallowing. The rehabilitation program consisted of daily sessions for two consecutive weeks during which a biofeedback resource adapted especially for this study was used. The patients were then reevaluated for swallowing ability at follow-up.

RESULTS: The patients presenting difficulties with swallowing water displayed no such problems after rehabilitation. Only one patient exhibited slow oral transit of food and other discrete oropharyngeal food remnants when swallowing a biscuit. The sample variance was used to analyze the pressure measurements, demonstrating a numerical similarity of the results obtained with the swallowing of saliva or of biscuits (VAR $=4.41)$. A statistical difference was observed between the swallowing of saliva and biscuits, showing a significant pressure increase at the end of the rehabilitation program $(\mathrm{p}<0.001)$.

CONCLUSION: The effortful swallow maneuver reinforced by using biofeedback appears to be a therapeutic resource in the rehabilitation of oropharyngeal dysphagia in Parkinson's disease patients.

KEYWORDS: Parkinson's disease; Oropharyngeal dysphagia; Rehabilitation; Effortful swallow; Biofeedback.

\section{INTRODUCTION}

In Brazil as well as the rest of the world, Parkinson's disease (PD) is becoming more and more prevalent as the world's population ages. Parkinson's disease is associated with the progressive degeneration of brainstem, mid-brain, subcortical, and cortical neurons. ${ }^{1}$

The disease is chronic and progressive, with a slow evolution of signs and symptoms, such as tremor, muscle rigidity, akinesia or bradykinesia and postural instability. ${ }^{2}$

It affects $1 / 1000$ people, and although life expectancy

IGastroenterology Department, Surgical Division, Faculdade de Medicina da Universidade de São Paulo - São Paulo/SP, Brazil.

INeurological Clinic, Physiotherapy Department, Taubaté University (UNITAU) - Taubaté/SP, Brazil.

Phone: 55113287.7456

Email: v.felix@terra.com.br

Received for publication on May 27, 2008

Accepted for publication on July 16, 2008 with current treatments is only 1.5 years less than the general population $^{3}$, there is a higher risk of pneumonia as a cause of death in PD patients, which is six times that of the normal population. This is thought to be due to a combination of chronic immobilization and swallowing impairment conditions. ${ }^{4}$

In the conditions of the disease itself, such as rigidity and bradykinesia, alterations in the voice, the articulation of words and oropharyngeal swallowing are commonly observed. $^{5}$

Previous studies have shown that $31-100 \%$ of patients with PD have some problem with swallowing. Drooling and difficulty swallowing saliva are present in up to $78 \%$ of patients, and of those with swallowing problems, $30 \%$ show signs of aspiration. ${ }^{6}$

The degenerative process may affect swallowing at all stages, but swallowing disturbances are a relatively late clinical manifestation in the course of the disease, even 
in spite of the early pathological changes of brainstem structures such as the dorsal motor nucleus of the vagus nerve. $^{?}$

Swallowing disturbances in PD may cause discomfort while eating, difficulties in taking oral medications, weight loss due to low caloric intake, and even dehydration because of the inability to swallow adequate liquids. ${ }^{8}$

Communication and food intake of PD patients are considerably affected. ${ }^{9-13}$ This leads to the patient being withdrawn and reserved, showing reluctance to agree even to interdisciplinary efforts seeking to improve their quality of life. It is even more difficult to convince them to take part in clinical protocols that seek to find new forms of treatment, which explains the paucity of literature regarding studies in therapeutic measures for swallowing disorders in PD patients. ${ }^{12}$

The current study investigates resources to provide better conditions for oropharyngeal swallowing with the goal of improving the quality of life for afflicted PD patients. We looked at the efficiency of the effortful swallow maneuver reinforced by the use of a biofeedback rehabilitation program for PD patients suffering from oropharyngeal dysphagia.

\section{MATERIALS AND METHODS}

Out of ten idiopathic PD patients treated under constant supervision at the Neurological Clinic of the Physiotherapy Department of Taubaté University, four patients suffering from oropharyngeal dysphagia for 18.5 months (5-36 months) agreed to participate in this study. All methods were approved by the Ethics Committee of the University.

The three men and one woman, all Caucasian, with an average age of 70.25 (66 -78) years, had been diagnosed with PD for an average of 9.25 years.

The level of clinical disability was rated using the Hoehn and Yahr scale. ${ }^{14}$ This rating scale ranges from stage I (being the mildest level of disability, consisting of symptoms such as unilateral involvement) to stage $\mathrm{V}$ (the most severe level of disability, to the point of wheelchair confinement).

The patients participating in this study were diagnosed as stage III. Their medication regimen was not changed during their participation in the study.

One patient was also under treatment for diabetes using a controlled diet. No other patient in this study was being treated for any other disease. All patients had been taking levodopa (200 mg) and Benserazide (50 mg) three times per day for approximately one year to treat the motor deficits caused by PD.

Neurologists and patients experienced with this regimen of medication have not reported any association between this therapy and swallowing disturbances.
Three patients suffered from frequent choking followed by coughing when they attempted to swallow solid foods, and suffered from delays in the oral preparatory phase and oropharyngeal transit of the bolus, referring to the experience as "food stuck in the throat." Using the O'Neel Dysphagia Severity Scale, ${ }^{15}$ patients were diagnosed with discrete oropharyngeal dysphagia.

Consistent with discrete/moderate oropharyngeal dysphagia, patients also had difficulty swallowing liquids. ${ }^{15}$ Additionally, patients exhibited a fear of aspiration of liquids each time they swallowed, which indeed occurred on many occasions.

Due to the difficulty in swallowing, all patients were reliant on pastes for meals since the consistency of the pastes allowed for better swallowing. As a result, eating had ceased to be an enjoyable act, producing instead depressive symptoms such as an increase in time spent at each meal (at least 25 minutes), at the end of which the patients were exhausted and embarrassed in front of their families.

\section{Clinical evaluation of swallowing}

Before and after the rehabilitation program for oropharyngeal dysphagia, patients were submitted to a clinical evaluation of swallowing, using liquids, pastes and solids for verification of dysfunction of oral transit, food remnants in the oral cavity and pharyngeal region and the alteration of the quality of voice. The presence of coughing and choking after swallowing were also evaluated for control purposes.

\section{Application of the effortful swallow maneuver}

The rehabilitation program consisted of daily sessions from Monday to Friday for two consecutive weeks.

Each session included eight maneuvers to aid swallowing, four involving saliva and the other four involving solids (biscuits). Biscuits were chosen as they have the hardest consistency to swallow, according to the patients.

The swallowing with effort maneuver is induced by requesting the patient to "swallow by contracting the muscles of the mouth and throat with the greatest possible force."

Subjects were submitted to the maneuvers at their midday meal to assess their usual mealtime swallowing process.

\section{Biofeedback}

During this maneuver, a biofeedback resource adapted especially for this study was used.

A balloon was inflated with $40 \mathrm{ml}$ of air and placed to the front of the cervical region. It was held firmly in place by an 
elastic neck fastener (Figure 1), guaranteeing that the same adjustments could be made in all sessions for each patient.

The balloon was connected to the pressure transducer by a plastic catheter, which in turn was connected to the digital manometer displaying the pressure (in $\mathrm{mmHg}$ ) exercised on the balloon. All the components of the biofeedback system are shown in Figure 2. The manometer was calibrated before each session to ensure the recorded pressure expressed the specific effort made for swallowing. The pressure measurements obtained in each effortful swallow maneuver were tabulated.

Using this method, the patient had the opportunity to observe the result of his/her effort, thus being constantly stimulated to achieve a higher number.

\section{RESULTS}

\section{Clinical}

The clinical data relating to before and after the rehabilitation program are shown in Table 1 . The patient that

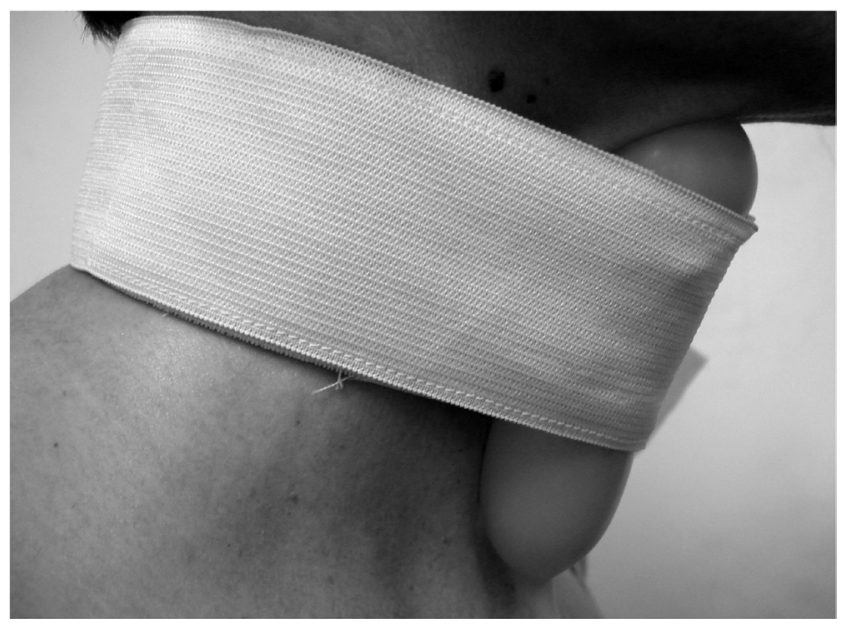

Figure 1 - The inflated balloon is placed to the front of the cervical region

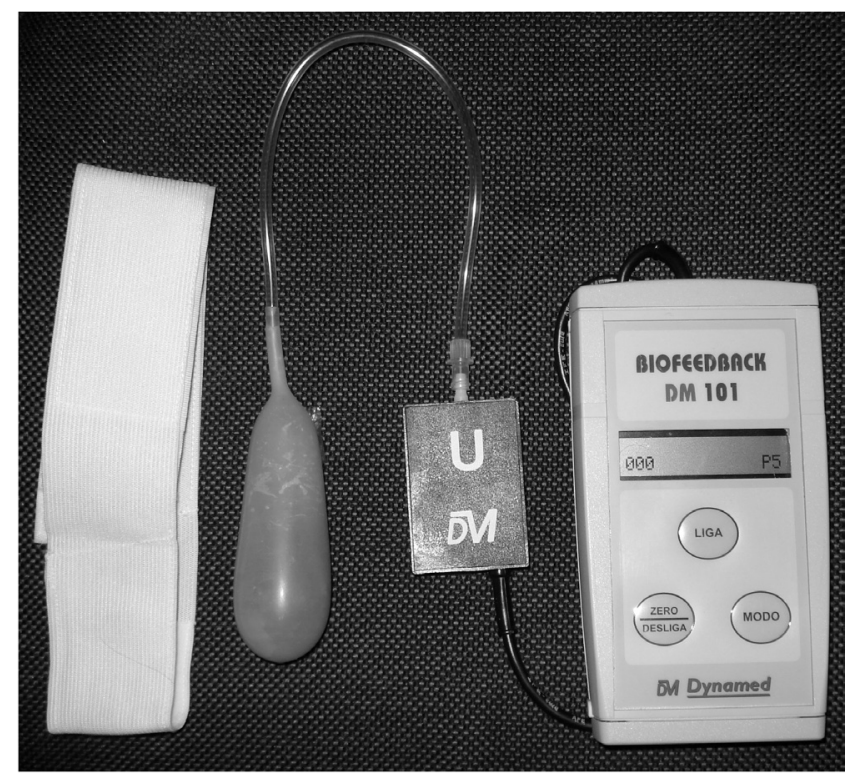

Figure 2 - Biofeedback resource adapted especially for this study

presented problems with swallowing water displayed no such problems after the rehabilitation.

One patient still showed slow oral transit of food and consequently had small amounts of oropharyngeal food remnants, but none of the patients exhibited difficulty in coughing, choking or voice alteration as a result of swallowing after participating in the rehabilitation program.

\section{Pressure measurements}

Pressure measurements obtained are shown in Figure 3 . The sample variance was used to analyze the pressure measurements registered over the ten days of training, and similarities were found between the results obtained with the swallowing of saliva and the swallowing of biscuits (VAR $=4.41$.

Table 1 - Results of the clinical evaluation of swallowing before (pre) and after (post) the rehabilitation program for oropharyngeal dysphagia

\begin{tabular}{|c|c|c|c|c|c|c|c|c|c|c|c|c|}
\hline \multirow{3}{*}{$\begin{array}{l}\text { CONSISTENCY } \\
\text { CLINICAL DISTURB }\end{array}$} & \multicolumn{4}{|c|}{ WATER } & \multicolumn{4}{|c|}{ YOGURT } & \multicolumn{4}{|c|}{ BISCUIT } \\
\hline & \multicolumn{2}{|c|}{ Pre } & \multicolumn{2}{|c|}{ Post } & \multicolumn{2}{|c|}{ Pre } & \multicolumn{2}{|c|}{ Post } & \multicolumn{2}{|c|}{ Pre } & \multicolumn{2}{|c|}{ Post } \\
\hline & $\mathrm{Y}$ & $\mathrm{N}$ & $\mathrm{Y}$ & $\mathrm{N}$ & $\mathrm{Y}$ & $\mathrm{N}$ & $\mathrm{Y}$ & $\mathrm{N}$ & $\mathrm{Y}$ & $\mathrm{N}$ & $\mathrm{Y}$ & $\mathrm{N}$ \\
\hline dysfunction of the oral transit & 1 & 3 & - & 4 & - & 4 & - & 4 & 4 & - & 1 & 3 \\
\hline food remnants in oral cavity and pharyngeal region & 1 & 3 & - & 4 & - & 4 & - & 4 & 4 & - & 1 & 3 \\
\hline alteration of the quality of voice after swallowing & 1 & 3 & - & 4 & - & 4 & - & 4 & 3 & 1 & - & 4 \\
\hline presence of coughing and choking after swallowing & 1 & 3 & - & 4 & - & 4 & - & 4 & 3 & 1 & - & 4 \\
\hline
\end{tabular}

$\mathrm{Y}$ number of patients with the clinical disturbs; $\mathrm{N}$ number of patients without the clinical disturbs 


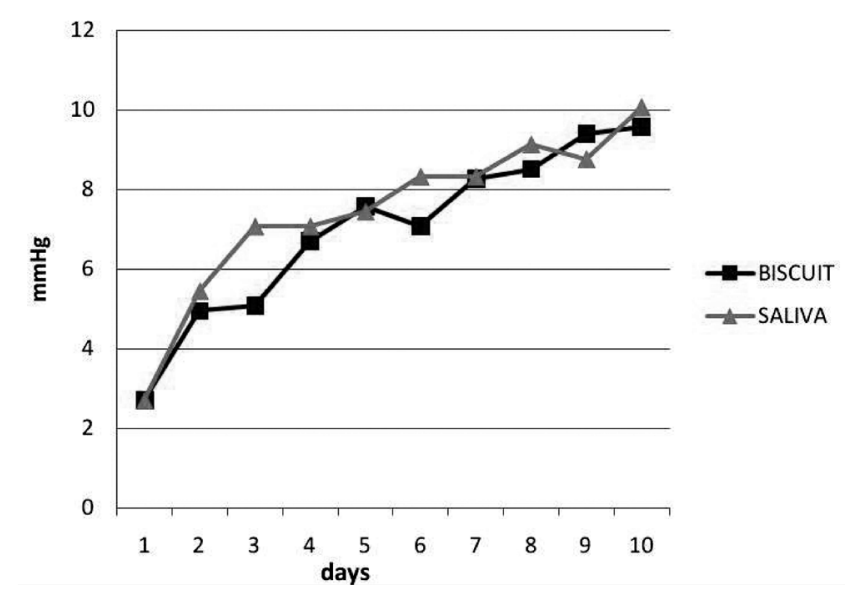

Figure 3 - Pressure measurements (mmhg) obtained with the swallowing of saliva or of biscuits, registered during the ten days of training

A Student's t-test was used to compare the effortful pressures obtained on the first and last day of conditioning. A significant increase in pressure was observed for both the swallowing of saliva and the biscuit at the end of the rehabilitation program $(\mathrm{p}<0.001)$.

\section{DISCUSSION}

Sporadic PD involves multiple neuronal systems and the pathological process targets specific induction sites. Lesions initially occur in the dorsal motor nucleus of the glossopharyngeal and vagal nerves as well as the anterior olfactory nucleus. Less vulnerable nuclear grays and cortical areas then gradually become affected and the disease process in the brainstem pursues an ascending course with little variation between patients. ${ }^{16}$ In $\mathrm{PD}$, the difficulty in swallowing may be caused by a change of the oral or pharyngeal phase. ${ }^{6}$

Oropharyngeal dysphagia, therefore, is one of the complications of PD and an increase in the oropharyngeal transit time and changes in laryngeal mobility may occur, making it necessary for patients to attend rehabilitation programs for swallowing improvement. ${ }^{17,18}$

A user-friendly questionnaire subjectively assessing swallowing disturbances in patients with PD has been proposed to be routinely administered during clinical visits with the hope that PD patients with swallowing disturbances will be found, evaluated, and treated at earlier stages to prevent aspiration pneumonia and to help maintain a good quality of life. ${ }^{19}$

Cases have been observed in which swallowing is compromised by the lack of coordination between the glottis closing and the relaxation of the upper esophageal sphincter. This results in an increase of waste in pharyngeal recesses, especially when pastes are used in the diet. ${ }^{20}$
A delay in the initiation of the swallowing reflex and prolonged laryngeal movement have been observed at the esophageal scintigraphy and electromyography in individuals with PD along with complaints of oropharyngeal dysphagia. ${ }^{21}$

It has also been reported that about half of Parkinson's patients have a significant index of swallowing complaints, ${ }^{6}$ which we also observed.

Oropharyngeal dysphagia may involve the dorsal motor nucleus of the vagus nerve. ${ }^{22}$ Symptoms may be due to rigidity and bradykinesia of the oropharyngeal muscles. ${ }^{12}$

There is disagreement in the literature regarding the association between the severity of PD and the presence and severity of dysphagia. Some studies, including this series, have found no association, ${ }^{23}$ whereas others have found a worsening of dysphagia with increasing severity of PD. ${ }^{24}$

Consistent with our findings, it is thought that patients may experience symptoms of dysphagia later in the course of PD compared to other parkinsonian disorders..$^{25}$

The rehabilitation of swallowing includes assessing the limitations of each patient in order to establish the training program that will be optimal for them. ${ }^{18}$ The goal of rehabilitation is to obtain better strength and mobility of the involved structures.

Indirect therapy may be used from the beginning without offering food to the patient. Therapy is limited to applying mobility exercises to the larynx, pharynx, tongue, cheeks, lips, soft palate and when closing the vocal folds.

The Lee Silverman Voice Treatment (LSVT®), for example, seemingly improved neuromuscular control of the entire upper aerodigestive tract, improving oral tongue and tongue base function during the oral and pharyngeal phases of swallowing as well as improving vocal intensity. ${ }^{26}$

After LSVT®, there was a 51\% reduction in the overall number of swallowing motility disorders. Some temporal measures of swallowing were also significantly reduced as well as the approximate amount of oral residue after $3 \mathrm{ml}$ and $5 \mathrm{ml}$ of liquid was swallowed. Another perspective on why LSVT® may improve swallowing comes from a PET study of voluntary swallowing in healthy volunteers. ${ }^{27}$

This study found that, in addition to the primary sensorimotor cortex (pharynx-larynx representation) and the brainstem, the other region most strongly activated during voluntary swallowing was the right anterior insular cortex, which is one of the sites that significantly changes with LSVT®. It is therefore likely that improved right anterior insular function (phylogenetically the "old communication system") may also contribute to the mechanism of improved voluntary swallowing following LSVT®.

Direct therapies such as postural maneuvers may also be used ${ }^{28}$ such as turning the chin downward, turning the head 
to the side, putting the head back to facilitate swallowing, forced coughing, the Mendelsohn Manoeuvre, placing the tongue between the teeth, the super-glottic, the super-supraglottic swallow technique, dry swallowing, Valsalva and the effortful swallow maneuver. In this study, we adopted the effortful swallow maneuver.

This maneuver is designed to improve the posterior movement of the base of the tongue and impede the accumulation of bolus retained in the valleculae.

Huckabee $(1992)^{20}$ observed that the population complaining of oropharyngeal dysphagia often presented with a weakness in the contraction of the pharynx muscles. These muscles are responsible for the propulsion of the bolus, resulting in pharyngeal accumulation during swallowing, thus producing a risk of aspiration.

The effortful swallow maneuver acts as a compensatory strategy to clean the pharynx region during meals as pharyngeal constriction increases.

The methods that use biofeedback have been highly valued in rehabilitation programs for many years. ${ }^{29,30}$ To this end, numbered charts, graphics, sounds, methods that use different colors for each stage reached, and any other reference for the patients to objectively measure their own progress has proven useful to help the patient achieve his/ her target.

We used biofeedback to reinforce the application of the effortful maneuver for the treatment of oropharyngeal dysphagia rehabilitation in PD patients.

The system used was originally designed for the rehabilitation of evacuation dysfunctions (DM 101 Dynamed( $).{ }^{31}$ For this study, we made special modifications to the original system.

The device was specifically designed to act as a biofeedback mechanism or to provide a comparative element between different efforts that encouraged patients to reach different pressures on the digital manometer display - the greater the force exerted, the bigger the difference.

We have shown, by using this method, that an improved performance is possible even when testing an element that is difficult for the patient to swallow (solid biscuit).

In PD, large numbers of neurons that synthesize the neurotransmitter dopamine are characteristically lost from the substantia nigra (a region of the mid-brain). Therapy with levodopa (a dopamine precursor) helps to replenish the dopaminergic deficit, but it does not restore intact cell function to affected neurons or stop the disease progression. $^{32}$

An interesting study further evaluated the risk of aspiration, in particular, the integration of swallowing and respiration "on" and "off" levodopa ${ }^{33}$ The "off" state was achieved by withholding any levodopa medication for at least $12 \mathrm{~h}$ before assessments were performed. Sections II (activities of daily living) and III (motor examination) of the Unified Parkinson's Disease Rating Scale (UPDRS) were applied. The scores obtained showed that motor function was significantly worse when "off" levodopa than when "on."

This pilot study also found that swallowing efficiency may be reduced with levodopa medication. No association was found between levodopa and coordination of swallowing and respiration, laryngeal penetration, or tracheal aspiration, indicating that the risk of aspiration may remain unchanged. This suggested that further studies comprising larger numbers of patients are needed to determine whether the trend in swallowing efficiency is a true effect and to confirm if there truly is no difference in risk of aspiration between "on" and "off" states of levodopa.

Although any test "off" levodopa was not authorized by the neurologists in this study, increased swallowing efficiency was demonstrated despite the continuous "on" state of levodopa.

Biofeedback has most likely played an important part in our findings, constituting an efficient stimulus that allowed solids to be swallowed almost without difficulty in the final two weeks of the rehabilitation program. These effects were mirrored by very satisfactory clinical evaluations (Table 1 ).

\section{CONCLUSION}

The effortful swallow maneuver reinforced with the use of biofeedback appears to be a therapeutic resource in the rehabilitation of oropharyngeal dysphagia in PD patients.

This pilot study (with only four patients) suggests that further evaluation with a larger number of patients is warranted.

\section{REFERENCES}

1. Braak H, Rub U, Gai WP Del Tredici K. Idiopathic Parkinson's disease: possible routes by which vulnerable neuronal types may be subject to neuroinvasion by an unknown pathogen. J Neural Transm. 2003;110:517-36.
2. Swinburn K, Morley R. Parkinson's disease: management pack clinicians's manual. Hampshire: Hobbs the Printers, 1997,340 p. 
3. Morgante L, Salemi G, Meneghini F, Di Rosa AE, Epifanio A, Grigoletto F, et al. Parkinson disease survival: a population-based study. Arch Neurol. 2000;57:507-12.

4. Fall PA, Saleh A, Fredrickson M, Olsson JE, Granérus AK. Survival time, mortality, and cause of death in elderly patients with Parkinson's disease: a 9-year follow-up. Mov Disord. 2003;18:1312-16.

5. Ramig LO, Countryman S, Thompson L, Horii Y. Comparison of two forms of intensive speech treatment for Parkinson disease. J Speech Lang Hear Res. 1995;38:1232-51.

6. Johnston BT, Li Q, Castell JA Castell DO. Swallowing and esophageal function in Parkinson's disease. Am J Gastroenterol. 1995;90:174146.

7. Monte FS, da Silva-Junior FP, Braga-Neto P Nobre e Souza MA, de Bruin VM. Swallowing abnormalities and dyskinesia in Parkinson's disease. Mov Disord. 2005;20:457-462.

8. Marik PE, Kaplan D. Aspiration pneumonia and dysphagia in the elderly. Chest. 2003;124:328-36.

9. Cardoso FE. Doença de Parkinson - Perspectivas Terapêuticas. Diálogo Científico. 2006;4:13-15.

10. Oliveira WCC. Influência da motivação e da ansiedade sobre a motricidade na doença de Parkinson. Disponível em http://www. parkinson.org/abp 3-98-canto e fonoaudiologia.htm. Consultado em 3 de agosto de 2007.

11. Kowacs PA. Causas neurológicas de disfagia em adulto. In: Macedo Filho E, Pissani JC, Carneiro J et al. Disfagia: Abordagem multidisciplinar. São Paulo, Frôntis, $2{ }^{a}$ Ed,1998. p.15-23.

12. Volonte MA, Porta M, Comi G. Clinical assessment of dysphagia in early phases of Parkinson's disease. Neurol Sci. 2002;23:S121-S122.

13. Rocha EMSS Disfagia. In: Marchesan, I.Q. Fundamentos em Fonoaudiologia: Aspectos clínicos da motricidade oral. Rio de Janeiro, Guanabara-Koogan, 1998. p. 91-95.

14. Hoehn M, Yahr M. Parkinsonism: onset, progression and mortality. Neurology (Minneap).1967;17:427-42.

15. O’Neil KH, Purdy M, Falk J, Gallo L. The Dysphagia Outcome and Severity Scale. Dysphagia. 1999;14:139-45.

16. Braak H, Tredici KD, Rüb U, de Vos RA, Jansen Steur EN, Braak E. Staging of brain pathology related to sporadic Parkinson's disease. Neurobiology of Aging 2003;24:197-211.

17. Furkim AM, Silva RG. Programas de Reabilitação em Disfagia Neurogênica. São Paulo: Frôntis Editorial. 1999. 52 p.

18. Felix VN. Dysphagia. A multidisciplinary approach. In: MorenoGonzalez E. Proceedings of the 17th World Congress of the International Association of Surgeons \& Gastroenterologists. Madrid: Jarpyo, 2007. p. 1-11.
19. Manor Y, Giladi N, Cohen A, Fliss DM, Cohen JT. Validation of a Swallowing Disturbance Questionnaire for Detecting Dysphagia in Patients with Parkinson's. Disease Movement Disorders. 2007;22:191721.

20. Huckabee ML Aplication of EMG biofeedback in the treatment of oral pharyngeal dysphagia. Electromyography. 1992;6:1-4.

21. Huckabee ML, Cannito M. Outcomes of swallowing reabilitation in chronic a brainstem dysphagia. A retrospective evaluation. Dysphagia. 1999;4:93-109.

22. Edwards LL, Quigley EM, Pfeiffer RF. Gastrointestinal dysfunction in Parkinson's disease: frequency and pathophysiology. Neurology. $1992 ; 42: 726-32$

23. Ali GN, Wallace KL, Schwartz R, DeCarle DJ, Zagami AS, Cook IJ. Mechanisms of oral-pharyngeal dysphagia in patients with Parkinson's disease. Gastroenterology. 1996;110:383-92.

24. Lam K, Lam FKY, Lau KK Chan YK, Kan EY, Woo J, et al. Simple Clinical Tests may Predict Severe Oropharyngeal Dysphagia in Parkinson's Disease. Movement Disorders. 2007;22:640-44.

25. Muller J, Wenning GK, Verny M McKee A, Chaudhuri KR, Jellinger K, et al. Progression of dysarthria and dysphagia in postmortem-confirmed parkinsonian disorders. Arch Neurol. 2001;58:259-64.

26. Sharkawi A El, Ramig L, Logemann JA. Swallowing and voice effects of (LSVT®): a pilot study. J Neurol Neurosurg Psychiatry. 2002;72:31-

27. Hamdy S, Rothwell JC, Brooks DJ Bailey D, Aziz Q, Thompson DG. Identification of the cerebral loci processing human swallowing with PET activation. J Neurophysiol. 1999;81:1917-26.

28. Crary MA. Direct intervention program for chronic neurogenic dysphagia secondary to brainstem stroke. Dysphagia. 1995;10:16-18.

29. Bryant MH, Bryant ML. Biofeedback in the treatment of a selected dysphagia patient. Dysphagia. 1991;6:140-44.

30. Corrêa SMA, Felix VN. Comparação de características da ativação da musculatura supra-hióidea com e sem utilização de biofeedback eletromiográfico: estudo preliminar. In: Felix VN, Viebig RG. São Paulo: CHP, 2007. p.113-114.

31. Viebig RG, Felix VN. Função anorretal normal e alterada. São Paulo: Dynamed, 2006. 96p.

32. Katzenschlager R, Lees AJ. Treatment of Parkinson's disease: Levodopa as the first choice. J Neurol. 2002;249:1119-24.

33. Lim A, Leow L, Huckabee ML, Frampton C, Anderson T. A Pilot Study of Respiration and Swallowing Integration in Parkinson's Disease: "On" and "Off" Levodopa. Dysphagia 2008;23:76-78 